\title{
Nepotism, Favoritism and Cronyism in faculty hiring among institutions providing higher education
}

\author{
Shekhawat, K. S.
}

"It's not what you know but who you know" An old saying commonly heard before and/or after attending an interview for hiring faculties in Indian universities. As brutal as it is, it perfectly resonates the antonym of what was once stated by Aristotle: "Equals should be treated equally and un-equals unequally". Unfortunately connections, referrals, bureaucracy, political involvement, similar family names - almost everyone has banked on these resources for support in job hunting both in Public and Private sector.

Every deemed university wishes to be the best in their respective domain. Their clear goals, mission and vision inscribed elegantly on plaques that are displayed outside their offices and within campuses often radiate an amazing commitment. The strength of any university to flourish, among other reasons is its faculty. Hiring faculties, to a large extent is proportional to human resource (HR) policies. An excellent faculty should be the core of any university, since any hardworking, focused employee is always an asset. Unfortunately, nepotism, favoritism and cronyism (NFC) has infiltrated the hiring process. Trailing spouses, relatives and kins are the perfect examples who get through the hiring process, what is sometimes called the back door.

How can universities whose goal is to be in the bracket of top 500 universities of the world achieve their goals, if their faculties are not selected based on merit and rather through back door. An employee selected through NFC may never work at all.

Corresponding Author:

Dr. Kuldeep Singh Shekhawat,

Associate Professor, Department of Public Health Dentistry, Century International Institute of Dental Sciences, Poinachi, Kasaragod, Kerala - 671541, India

E mail:drkuldeepss@gmail.com
The contribution may/will never be for the best interest of the department, least for the institution. The candidate will always be under the umbrella of NFC and will always bank on the same for further professional growth.

If people are given positions for which they do not have the relevant skills, training or experience, they are unlikely to perform well as when compared to those hired on merit and good performance. It does surprises everyone, when someone from outside with merit, often perceives it next to impossible to get a position and finds out that someone else has obtained a position that was never even posted or was posted only as a formality. Many qualified and deserving candidates are not searched and selected, but are rather expected to apply with majority simply not even aware of the vacancies.

In addition, recommendations/referral reports from established and credible names or institutions for any undeserving candidate plays a crucial role in recruitment process. Since, recruiters feel more confident about the candidate when they receive such recommendations. In some cases, positions and criteria's are specifically crafted to meet the qualification and experience of spouses/friends/relatives or persons with similar surnames (in some cases) that are commonly unnecessary to the function of the institution. At times, extensions are given to senior faculties merely on the basis of their seniority in their respective institutions/universities. This obliterates any chances for new deserving candidate at the baseline. New faculties' at most Indian institutions, on occasion, do get hired on merit. Some institutions/universities tend to hire their own-those who have completed their Masters/PhDs at the home institution-at the expense of better-qualified candidates from 
elsewhere, giving rise to institutional inbreeding.

Nevertheless, universities often shield NFC by citing such hiring process as promoting dualcareer. It is their understanding that such hiring promotes work productivity since both the spouses are assured of a job. They also assert that it increases loyalty, adds stability to the university among other arguments, and that people who are provided jobs this way are suitably qualified (Robbins, 2013). Though not illegal, but from an institutional integrity and performance point of view, such initiation is prejudiced and very inefficient. Faculties hired on NFC could have a reverse effect on faculty development, since resources that could have been used for something, or for more pressing requirements needs to be paid as salaries. In addition, lack of an open and competitive search could be a particularly dispiriting, and promote cynicism-breeding, practice (Pushkar, 2015).

Nevertheless, employees hired on NFC can also be an asset. Some employees are hired to help universities achieve their goal within a specific time frame. Some are even picked-up after carefully analyzing associated profit and/or loss that comes with hiring (employee on $\mathrm{NFC}$ ). If the hired employee (based on NFC) helps the university acquire millions of dollars (or crores in INR) in the form of grants for any research project, or helps the university move up the ladder globally, then such moves are justified in the long run.
However, it's a common view that NFC do interfere with 'fairness' at all levels simply because undue advantage is given to someone since he/she either happens to be a family member, or a friend or associate or belong to any favored group sharing common likes and dislikes. NFC could be a reason for lack of productivity that may bring about negative attitude towards the organization and decreases reliance on institutions (Aydogan, 2009). This may handicap an entire institutional organization. NFC is an unavoidable situation and/or an open secret that no one wants to talk about, since every move made during hiring process have justifications. Is it undermining the foundation of Indian universities? Or perhaps has corroded the caliber of meritorious candidates. Will steps be taken to create more transparency? We can only hope for the best.

\section{References}

Aydogan, I. (2009) Favoritism in the Turkish Educational System: Nepotism, Cronyism and Patronage, Online Submission, 4, 1

Robbins, J. (2013) Is academic nepotism a good thing? Available at: https://www.insidehighered.com/blogs/soundin g-board/academic-nepotism-good-thing (Last accessed 5 Aug 2017)

Pushkar, D. (2015) Straight Talk: Put Merit First in Indian Education, Braingainmag, Available at: https://www.braingainmag.com/straight-talk (Last accessed on 5 Aug 2017) 